\title{
Prognostic importance of the inflammation-based Glasgow prognostic score in patients with gastric cancer
}

\author{
X Jiang ${ }^{1,2}$, N Hiki,', S Nunobe', K Kumagai', T Kubota', S Aikou', T Sano' and T Yamaguchi' \\ 'Department of Gastroenterological Surgery, Gastroenterological Center, Cancer Institute Hospital, Japanese Foundation for Cancer Research, 3-8-3 I \\ Ariake, Koto-ku, Tokyo 135-8550, Japan; '2Department of General Surgery, Zhongda Hospital, Southeast University, Nanjing, China
}

\begin{abstract}
BACKGROUND: The inflammation-based Glasgow prognostic score (GPS) has been shown to be a prognostic factor for a variety of tumours. This study investigates the significance of the modified GPS (mGPS) for the prognosis of patients with gastric cancer. METHODS: The mGPS $\left(0=\right.$ C-reactive protein $(C R P) \leqslant 10 \mathrm{mg}^{-1}, \quad|=C R P>| 0 \mathrm{mg}^{-1}$ and $2=C R P>|0 \mathrm{mg}|^{-1}$ and albumin $<35 \mathrm{gl}^{-1}$ ) was calculated on the basis of preoperative data for 1710 patients with gastric cancer who underwent surgery between January 2000 and December 2007. Patients were given an mGPS of 0, I or 2. The prognostic significance was analysed by univariate and multivariate analyses.

RESULTS: Increased mGPS was associated with male patient, old age, low body mass index, increased white cell count and neutrophils, elevated carcinoembryonic antigen and CA I9-9 and advanced tumour stage. Kaplan-Meier analysis and log-rank test revealed that a higher mGPS predicted a higher risk of postoperative mortality in both relative early-stage (stage I; $P<0.00 \mathrm{I}$ ) and advanced-stage cancer (stage II, III and IV; $P<0.00 \mathrm{I}$ ). Multivariate analysis demonstrated the mGPS to be a risk factor for postoperative mortality (odds ratio I.845; 95\% confidence interval I. I84-2.875; $P=0.007$ ).

CONCLUSION: The preoperative mGPS is a simple and useful prognostic factor for postoperative survival in patients with gastric cancer. British Journal of Cancer (2012) I 07, 275-279. doi:I0.1038/bjc.2012.262 www.bjcancer.com

Published online 19 June 2012

(c) 2012 Cancer Research UK
\end{abstract}

Keywords: gastric cancer; C-reactive protein; albumin; prognostic score; survival

Gastric cancer is the fourth most common cancer worldwide, and the second most frequent cause of mortality (Crew and Neugut, 2006; Kamangar et al, 2006). In Japan, although the incidence of gastric cancer has decreased, gastric cancer remains the most frequent cause of morbidity among patients with malignant tumours (Inoue and Tsugane, 2005). Although recent years have seen improvements in surgical techniques and adjuvant chemotherapy, the long-term survival of patients with advanced-stage gastric cancer remains unsatisfactory (Sasako et al, 2008).

There is increasing evidence that, in addition to tumour stage and the proliferative activity of tumour cells, the systemic inflammatory response is associated with malignancy (Roxburgh et al, 2009; McArdle et al, 2010; Richards et al, 2010). C-reactive protein (CRP), an acute-phase response protein, has been proven to be an independent prognostic factor for survival in many malignancies, including gastric cancer (Jagdev et al, 2010; Roxburgh and McMillan, 2010). In addition, hypoalbuminemia, a typical index of malnutrition, has been reported to be associated with poor survival in advanced cancer (Crumley et al, 2010; Lai et al, 2010). Recently, the Glasgow prognostic score (GPS), based on serum CRP and albumin levels, was developed to aid in the assessment of cancer prognosis (Ishizuka et al, 2009; Richards et al, 2010). An elevated GPS has been shown to be associated with worse prognosis for a number of different tumours (McMillan, 2009). Thus, the GPS may be a prognostic marker in cancer,

*Correspondence: Dr N Hiki, E-mail: naoki.hiki@jfcr.or.jp Received I March 2012; revised II May 2012; accepted II May 20 I2; published online 19 June 2012 independent of stage and biochemical tumour markers (McMillan, 2009; Roxburgh et al, 2009).

The GPS has also been shown to be a prognostic factor in advanced gastrointestinal cancers, including oesophageal and colorectal cancer (Kobayashi et al, 2008; Ishizuka et al, 2009). However, only few studies have used the GPS for postoperative prognostication of patients with gastric cancer. Thus, in the present study, we collected data retrospectively from 1710 patients with operable gastric cancer and investigated the significance of the preoperative GPS for postoperative survival in these patients.

\section{MATERIALS AND METHODS}

The gastric cancer database from the Department of Gastroenterological Surgery at The Cancer Institute Hospital, Tokyo, Japan, was reviewed retrospectively. Patients with gastric adenocarcinoma who had undergone curative (R0 resection) or palliative gastrectomy between January 2000 and December 2007 and for whom preoperative laboratory data for CRP and albumin were available were enrolled into the study. Palliative surgery is defined as the presence of any gross or microscopic residual tumours remaining postoperatively regardless of whether the surgical attempt was originally palliative or curative. Patients who died within 30 days after surgery, or those who died of non-cancerrelated causes were excluded from the study. Patients who had other malignancies or who had inflammatory diseases that might have increased CRP levels were also excluded from the study. To remove any influence of neoadjuvant chemo/radiotherapy on survival or GPS, patients who received neoadjuvant chemotherapy 
or radiotherapy were also excluded. Using these criteria, 1710 patients with gastric cancer were enrolled in the present study. Patients were followed according to the established protocol in our hospital, including medical history, physical examination and laboratory studies 1 and 3 months after operation, and then every 6 months.

Pathological tumour stage (pTNM) was determined using the seventh edition of the AJCC cancer staging of stomach (Washington, 2010). Blood samples were collected for routine laboratory measurements of CRP, albumin, complete blood count and tumour markers such as carcinoembryonic antigen (CEA) (cutoff value, $5 \mathrm{ng} \mathrm{ml}^{-1}$ ) and CA19-9 (cutoff value, $37 \mathrm{ng} \mathrm{ml}^{-1}$ ). The modified GPS (mGPS) was calculated as described previously (Leitch et al, 2007). Briefly, patients with elevated CRP ( $>10 \mathrm{mgl}^{-1}$ ) were assigned an mGPS of 1 or 2 depending on the absence or presence of hypoalbuminaemia $\left(<35 \mathrm{gl}^{-1}\right)$, whereas patients showing no elevated level of CRP $\left(\leqslant 10 \mathrm{mgl}^{-1}\right)$ are allocated an mGPS of 0 , even if hypoalbuminaemia is present.

\section{Statistical analysis}

Data are presented as mean and 95\% confidence intervals (CI). Differences between groups were analysed using the Kaplan-Meier survival analysis or $\chi^{2}$ test. Survival analysis was performed using Cox proportional hazards model in a forward stepwise manner. Kaplan-Meier analysis and log-rank test were used to compare mortality for each mGPS. Deaths before 31 July 2010 were included in this analysis. $P<0.05$ was considered significant. All statistical analyses were performed using SPSS version 13.0 (SPSS, Chicago, IL, USA).

\section{RESULTS}

During 2000-07, 2601 patients underwent gastric cancer surgery. Of these, 845 were excluded from analysis because data on their CRP and albumin levels were not available, and 46 were excluded because of neoadjuvant chemotherapy, postoperative death or non-cancer death. Of the 1710 included patients with gastric cancer (1157 men; 553 women), 240 (14.0\%) had elevated CRP levels $\left(>10 \mathrm{mgl}^{-1}\right)$ and/or hypoalbuminemia $\left(<35 \mathrm{gl}^{-1}\right)$. Of these, $78(4.6 \%)$ were given an mGPS of 1 and $67(3.9 \%)$ were given an mGPS of 2. The median follow-up time was 43.0 (1-123) months. None of the patients was lost to follow-up.

The classified background demographics and their association with overall survival are given in Table 1 . There was no significant difference in overall survival in terms of sex (male/female), white cell count $\left(<11 / \geqslant 11 \times 10^{9} 1^{-1}\right)$ and lymphocytes $(<3 / \geqslant 3 \times$ $\left.10^{9} 1^{-1}\right)$. Conversely, significant differences in overall survival were found in relation to age ( $<65 / \geqslant 65$ years), body mass index (BMI; <18.5/18.5-25/ $>25 \mathrm{~kg} \mathrm{~m}^{-2}$ ), tumour location (upper/middle/lower third), neutrophils $\left(<7.5 / \geqslant 7.5 \times 10^{9} 1^{-1}\right)$, CEA $(\leqslant 5 /$ $\left.>5 \mathrm{ng} \mathrm{ml}^{-1}\right), \quad$ CA19-9 $\left(\leqslant 37 />37 \mathrm{ng} \mathrm{ml}^{-1}\right), \quad$ CRP $\quad(\leqslant 10 /$ $\left.>10 \mathrm{mgl}^{-1}\right)$, albumin $\left(<35 / \geqslant 35 \mathrm{gl}^{-1}\right)$, tumour stage (I/II/III/ IV) and mGPS (0/1/2).

The relationship between clinicolaboratory characteristics and mGPS is given in Table 2. Sex, age, BMI, white cell count, neutrophils, CEA, CA19-9 and tumour stage showed significant relationship with the mGPS. Conversely, mGPS was not affected by tumour location and lymphocytes.

Univariate analysis of postoperative mortality is indicated in Table 3. Seven factors were significantly associated with overall survival including age, BMI, neutrophils, CEA, CA19-9, tumour stage and mGPS. On multivariate analysis, factors with $P<0.1$ in univariate analysis were included. Multivariate analysis revealed a significant association between postoperative mortality and age (odds ratio (OR), 1.319; 95\% CI, 1.068-1.629; $P=0.010$ ), tumour
Table I Clinical and laboratory characteristics associated with overall survival

\begin{tabular}{|c|c|c|c|}
\hline & $\begin{array}{l}\text { No. of } \\
\text { patients }\end{array}$ & $\begin{array}{l}\text { Overall survival (months), } \\
\text { mean }(95 \% \mathrm{Cl})\end{array}$ & $P$-value ${ }^{a}$ \\
\hline \multicolumn{4}{|l|}{ Sex } \\
\hline Male & 1157 & $90.0(87.0-93.0)$ & \multirow[t]{2}{*}{0.185} \\
\hline Female & 553 & $96.2(91.9-100.5)$ & \\
\hline \multicolumn{4}{|l|}{ Age (years) } \\
\hline$<65$ & 885 & 98.1 (94.7-101.4) & \multirow[t]{2}{*}{$<0.001$} \\
\hline$\geqslant 65$ & 813 & $85.9(82.1-89.8)$ & \\
\hline \multicolumn{4}{|c|}{ Body mass index $\left(\mathrm{kg} \mathrm{m}^{-2}\right)$} \\
\hline$<18.5$ & 261 & $61.4(55.8-67.0)$ & \multirow[t]{3}{*}{$<0.001$} \\
\hline 18.5-25 & 1138 & $96.1(93.0-99.2)$ & \\
\hline$\geqslant 25$ & 233 & $96.1(91.4-100.9)$ & \\
\hline \multicolumn{4}{|l|}{ Tumour location } \\
\hline Upper third & 460 & $79.2(74.6-83.8)$ & \multirow[t]{3}{*}{$<0.001$} \\
\hline Middle third & 772 & $100.5(96.9-104.2)$ & \\
\hline Lower third & 470 & $88.2(83.1-93.3)$ & \\
\hline \multicolumn{4}{|c|}{ White cell count $\left(\times 10^{9} 1^{-1}\right)$} \\
\hline$<\mid 1$ & 1682 & $93.3(90.7-96.0)$ & \multirow[t]{2}{*}{0.156} \\
\hline$\geqslant 11$ & 27 & $60.4(48.7-72.2)$ & \\
\hline \multicolumn{4}{|c|}{ Neutrophils $\left(\times 10^{9} 1^{-1}\right)$} \\
\hline$<7.5$ & 1605 & $94.0(91.4-96.7)$ & \multirow[t]{2}{*}{$<0.001$} \\
\hline$\geqslant 7.5$ & 50 & $59.2(46.1-72.3)$ & \\
\hline \multicolumn{4}{|c|}{ Lymphocytes $\left(\times 10^{9} 1^{-1}\right)$} \\
\hline$<3$ & 1592 & $92.9(90.2-95.6)$ & \multirow[t]{2}{*}{0.208} \\
\hline$\geqslant 3$ & 63 & $95.0(85.4-104.6)$ & \\
\hline \multicolumn{4}{|l|}{$\operatorname{CEA}\left(n g m l^{-1}\right)$} \\
\hline$\leqslant 5$ & 1433 & $95.4(92.7-98.1)$ & \multirow[t]{2}{*}{$<0.001$} \\
\hline$>5$ & 233 & $55.9(49.9-61.8)$ & \\
\hline \multicolumn{4}{|c|}{ CAl9-9 $\left(\mathrm{ng} \mathrm{ml}^{-1}\right)$} \\
\hline$\leqslant 37$ & 1406 & 94.1 (91.4-96.8) & \multirow[t]{2}{*}{$<0.001$} \\
\hline$>37$ & 151 & $48.5(40.4-56.5)$ & \\
\hline \multicolumn{4}{|l|}{$\operatorname{CRP}\left(m g l^{-1}\right)$} \\
\hline$\leqslant 10$ & 1565 & $95.8(93.2-98.5)$ & \multirow[t]{2}{*}{$<0.001$} \\
\hline$>10$ & 145 & $51.4(44.5-58.2)$ & \\
\hline \multicolumn{4}{|l|}{ Albumin $\left(g l^{-1}\right)$} \\
\hline$<35$ & 162 & $38.8(33.0-44.5)$ & \multirow[t]{2}{*}{$<0.001$} \\
\hline$\geqslant 35$ & 1548 & $97.8(95.2-100.4)$ & \\
\hline \multicolumn{4}{|c|}{ Tumour stage (PTNM) } \\
\hline I & 997 & | $13.5(|| 1.0-1 \mid 6.0)$ & \multirow{4}{*}{$<0.001$} \\
\hline ॥ & 200 & $82.6(77.2-87.9)$ & \\
\hline III & 245 & $68.1(62.0-74.1)$ & \\
\hline IV & 268 & $28.7(23.9-33.5)$ & \\
\hline \multicolumn{4}{|l|}{ mGPS } \\
\hline 0 & 1565 & 95.8 (93.2-98.5) & $<0.001$ \\
\hline I & 78 & $62.2(53.4-7 \mid .1)$ & \\
\hline 2 & 67 & $35.9(27.0-44.8)$ & \\
\hline
\end{tabular}

Abbreviations: $\mathrm{CEA}=$ carcinoembryonic antigen; $\mathrm{CRP}=\mathrm{C}$-reactive protein; $\mathrm{mGPS}=$ modified Glasgow prognostic score; pTNM = pathological tumour-node-metastasis staging. ${ }^{a}$ Kaplan-Meier survival analysis.

stage (OR, 2.909; 95\% CI, 2.616-3.234; $P<0.001$ ) and the mGPS (OR, 1.845; 95\% CI, 1.184-2.875; $P=0.007$ ) (Table 3).

The mean survival of patients with an mGPS of 0,1 and 2 was 95.8, 62.2 and 35.9 months, respectively (Table 1). Kaplan-Meier analysis and log-rank test demonstrated significant differences among patients with mGPS of 0,1 and $2(P<0.001)$, with the mortality rate higher for patients with a higher mGPS (Figure 1). 
Table 2 Relationships between clinicolaboratory characteristics and mGPS

\begin{tabular}{|c|c|c|c|c|}
\hline & $\begin{array}{c}\text { mGPS } 0 \\
\text { n (\%) }\end{array}$ & $\begin{array}{c}\text { mGPS I } \\
\text { n (\%) }\end{array}$ & $\begin{array}{c}\text { mGPS } 2 \\
\text { n (\%) }\end{array}$ & $P$-value ${ }^{a}$ \\
\hline \multicolumn{5}{|l|}{ Sex } \\
\hline Male & 1045 (90.3) & $60(5.2)$ & $52(4.5)$ & \multirow[t]{2}{*}{0.036} \\
\hline Female & $520(94.0)$ & $18(3.3)$ & $15(2.7)$ & \\
\hline \multicolumn{5}{|l|}{ Age (years) } \\
\hline$<65$ & 831 (93.9) & $29(3.3)$ & $25(2.8)$ & \multirow[t]{2}{*}{0.001} \\
\hline$\geqslant 65$ & $723(88.9)$ & $48(5.9)$ & $42(5.2)$ & \\
\hline \multicolumn{5}{|c|}{ Body mass index $\left(\mathrm{kg} \mathrm{m}^{-2}\right)$} \\
\hline$<18.5$ & $212(81.2)$ & $17(6.5)$ & $32(12.3)$ & \multirow[t]{3}{*}{$<0.001$} \\
\hline | $8.5-25$ & $1059(93.1)$ & $47(4.1)$ & $32(2.8)$ & \\
\hline$\geqslant 25$ & $221(94.8)$ & II (4.7) & I (0.4) & \\
\hline \multicolumn{5}{|l|}{ Tumour location } \\
\hline Upper third & $414(90.0)$ & $22(4.8)$ & $24(5.2)$ & \multirow[t]{3}{*}{0.069} \\
\hline Middle third & $722(93.5)$ & $29(3.8)$ & $21(2.7)$ & \\
\hline Lower third & $421(89.6)$ & $27(5.7)$ & $22(4.7)$ & \\
\hline \multicolumn{5}{|c|}{ White cell count $\left(\times 101^{-1}\right)$} \\
\hline$<11$ & $1556(92.5)$ & $70(4.2)$ & $56(3.3)$ & \multirow[t]{2}{*}{$<0.001$} \\
\hline$\geqslant 11$ & $8(29.6)$ & $8(29.6)$ & II (40.7) & \\
\hline \multicolumn{5}{|c|}{ Neutrophils $\left(\times 10^{9} 1^{-1}\right)$} \\
\hline$<7.5$ & $1498(93.3)$ & $65(4.0)$ & $42(2.6)$ & \multirow[t]{2}{*}{$<0.001$} \\
\hline$\geqslant 7.5$ & $19(38.0)$ & $12(24.0)$ & $19(38.0)$ & \\
\hline \multicolumn{5}{|c|}{ Lymphocytes $\left(\times 10^{9} 1^{-1}\right)$} \\
\hline$<3$ & $1458(91.6)$ & $75(4.7)$ & $59(3.7)$ & \multirow[t]{2}{*}{0.633} \\
\hline$\geqslant 3$ & $59(93.7)$ & $2(3.2)$ & $2(3.2)$ & \\
\hline \multicolumn{5}{|l|}{$\operatorname{CEA}\left(n g m l^{-1}\right)$} \\
\hline$\leqslant 5$ & I $342(93.6)$ & $56(3.9)$ & $25(2.4)$ & \multirow[t]{2}{*}{$<0.001$} \\
\hline$>5$ & I $84(79.0)$ & $20(8.6)$ & $29(12.4)$ & \\
\hline \multicolumn{5}{|c|}{ CAl9-9 $\left(\mathrm{ng} \mathrm{ml}^{-1}\right)$} \\
\hline$\leqslant 37$ & $1299(92.4)$ & $57(4.1)$ & $50(3.6)$ & \multirow[t]{2}{*}{0.006} \\
\hline$>37$ & $128(84.8)$ & $12(7.9)$ & $11(7.3)$ & \\
\hline \multicolumn{5}{|l|}{ Tumour stage } \\
\hline 1 & $96 \mid(96.4)$ & $30(3.0)$ & $6(0.6)$ & \multirow[t]{4}{*}{$<0.001$} \\
\hline ॥ & $177(88.5)$ & $9(4.5)$ & $14(7.0)$ & \\
\hline III & $219(89.4)$ & $13(5.3)$ & $13(5.3)$ & \\
\hline IV & $208(77.6)$ & $26(9.7)$ & $34(12.7)$ & \\
\hline
\end{tabular}

Abbreviations: $C E A=$ carcinoembryonic antigen; $\mathrm{mGPS}=$ modified Glasgow prognostic score. ${ }^{a} \chi^{2}$ test.

To clarify whether the mGPS has different prognostic value depending on tumour stage, patients were divided into two groups, namely those with relatively early-stage tumours (stage I; $n=997$ ) and those with advanced-stage tumours (stage II, III and IV; $n=713$ ). Significant differences in survival were found for patients with mGPS of 0,1 and 2 in both groups (both $P<0.001$ ) (Figures 2 and 3 ).

\section{DISCUSSION}

The present retrospective study analysed individual clinical data for 1710 patients who underwent surgery for a pure cohort of gastric cancer in a high-volume center in Japan. The results demonstrate the prognostic value of the mGPS for gastric cancer. Although the GPS has been reported to have prognostic significance in a variety of cancers, its value in gastric cancer has not been fully investigated (Elahi et al, 2004; Crumley et al,
Table 3 Univariate and multivariate analyses of overall survival

\begin{tabular}{|c|c|c|c|c|c|c|}
\hline & \multicolumn{3}{|c|}{ Univariate analysis } & \multicolumn{3}{|c|}{ Multivariate analysis $^{\mathrm{a}}$} \\
\hline & $\begin{array}{c}P \text { - } \\
\text { value }\end{array}$ & $\begin{array}{l}\text { Odds } \\
\text { ratio }\end{array}$ & $95 \% \mathrm{Cl}$ & $\begin{array}{c}P \text { - } \\
\text { value }\end{array}$ & $\begin{array}{l}\text { Odds } \\
\text { ratio }\end{array}$ & $95 \% \mathrm{Cl}$ \\
\hline Sex & 0.187 & & $0.706-1.070$ & - & - & - \\
\hline & & & & 0.010 & & \\
\hline ass index & $<0.001$ & 0.503 & 0.419 & 0.2 & 0.8 & \\
\hline & & 0.8 & & 0.2 & 0.929 & $0.8|3-1.06|$ \\
\hline II count & 0.161 & 1.567 & $0.837-2.933$ & & - & \\
\hline & $<0.00$ & & & 0.153 & 0.681 & $0.402-1.153$ \\
\hline Lymphocytes & 0.212 & 0.693 & $0.391-1.231$ & & - & \\
\hline $\begin{array}{l}\text { CEA } \\
\text { CAI9-9 }\end{array}$ & $\begin{array}{l}<0.001 \\
<0.001\end{array}$ & $\begin{array}{l}3.121 \\
4.059\end{array}$ & $\begin{array}{l}2.518-3.868 \\
3.189-5.168\end{array}$ & $\begin{array}{l}0.107 \\
0.177\end{array}$ & $\begin{array}{l}1.234 \\
1.213\end{array}$ & $\begin{array}{l}0.955-1.595 \\
0.916-1.605\end{array}$ \\
\hline Tumour stage & $<0.001$ & 2.974 & $2.724-3.247$ & $<0.001$ & 2.909 & $2.616-3.234$ \\
\hline mGPS $(0$, I and 2$)$ & $<0.001$ & 4.578 & $3.324-6.306$ & 0.007 & 1.845 & $1.184-2.875$ \\
\hline
\end{tabular}

Abbreviations: $C E A=$ carcinoembryonic antigen; $m G P S=$ modified Glasgow prognostic score. ${ }^{a}$ Factors $<0.10$ in univariate analysis were included in the multivariate analysis.

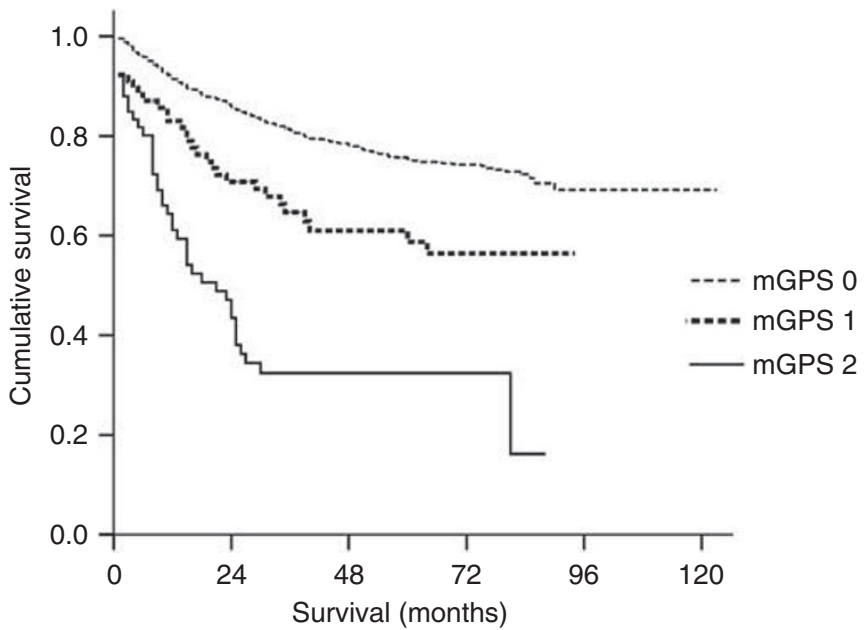

Figure I Relationship between the mGPS (mGPS 0, I, 2 from top to bottom) and overall survival in patients with gastric cancer.

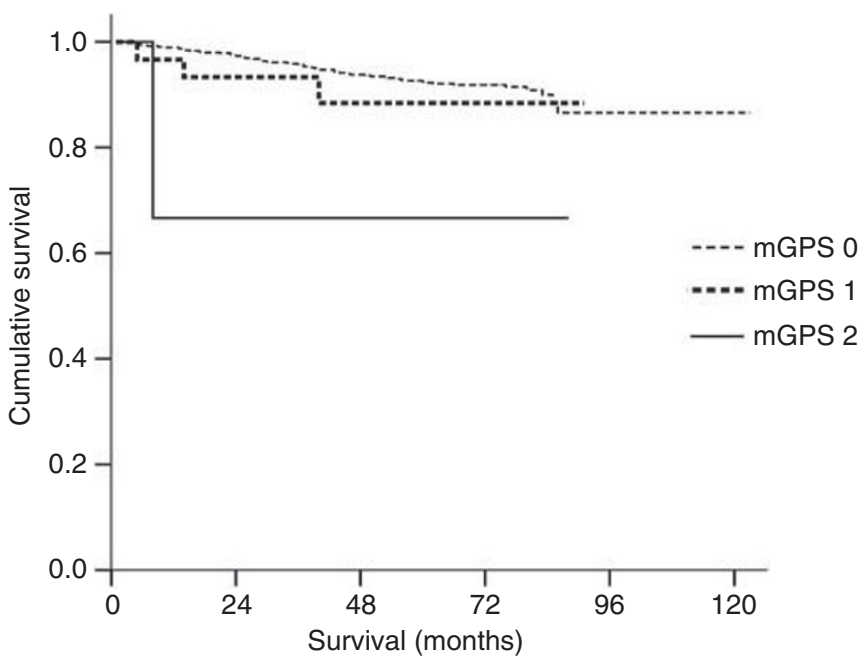

Figure 2 Relationship between the mGPS (mGPS 0, 1, 2 from top to bottom) and overall survival in patients with relatively early gastric cancer (stage I). 


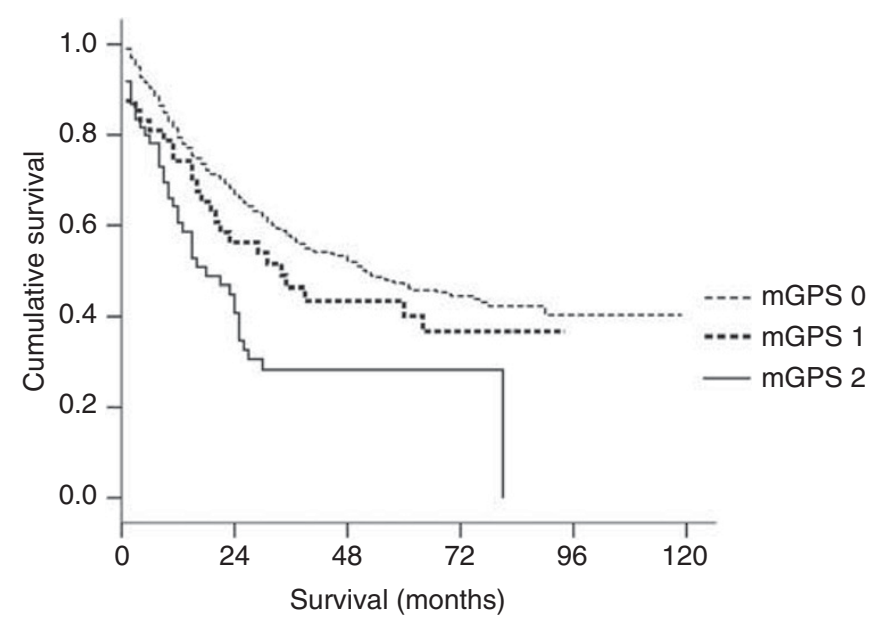

Figure 3 Relationship between the mGPS (mGPS 0, I, 2 from top to bottom) and overall survival in patients with advanced gastric cancer (stage II, III and IV).

2006; Nozoe et al, 2011). Furthermore, the GPS is usually considered to be correlated with postoperative survival only in very advanced cancer (Ishizuka et al, 2009; Roxburgh et al, 2009; Shimoda et al, 2010). The present study included patients with gastric cancer who underwent gastrectomy; and the prognostic value of the mGPS in not only very advanced but also relatively early gastric cancer was evaluated. Currently, pathological TNM is considered the gold standard for predicting postoperative outcome, but it can only be properly evaluated postoperatively. On the other hand, preoperative TNM is not always accurate, and this causes the difficulty and bias for predicting survival preoperatively. The results of the present study indicate that the mGPS can predict postoperative survival for patients with gastric cancer. More importantly, the mGPS can be achieved easily before operation, and it seems not inferior to conventional tumour markers like CEA and CA19-9.

Numerous studies have reported that elevated CRP levels are indicative of a poor outcome in a variety of cancers (Koike et al, 2008; Jagdev et al, 2010; Roxburgh and McMillan, 2010). For example, elevated CRP levels have been reported to be independent prognostic factors associated with tumour size, cancer stage, cancer cachexia and poor prognosis in many studies (Nozoe et al, 2001; Koike et al, 2008). Kim et al (2009) reported a correlation between CRP levels and depth of invasion, lymph node metastasis and TNM stage in operable gastric cancer. Crumley et al (2010) reported that elevated CRP levels were a significant predictor of survival in gastric cancer. In the present study, the mean survival time of patients with elevated CRP levels $\left(>10 \mathrm{mgl}^{-1}\right)$ was significantly lower than that of patients with normal CRP levels $\left(\leqslant 10 \mathrm{mgl}^{-1}\right)$, which emphasises the correlation between CRP levels and prognosis.

Hypoalbuminemia is often observed in advanced cancer patients, and is usually regarded as a good index for malnutrition and cachexia. In gastric cancer, hypoalbuminemia is reported to be associated with poorer survival (Lien et al, 2004; Crumley et al, 2010), which was also observed in the present study. Previous studies have indicated that hypoalbuminemia is likely to develop secondary to increases in serum CRP levels (Al-Shaiba et al, 2004). Furthermore, study of Crumley et al (2010) demonstrated that the relation of low albumin concentrations and poorer survival in patients with gastric cancer was dependent on the elevated CRP level. In the present study, hypoalbuminemia was significantly correlated with serum elevation of CRP (data not shown). So systemic inflammatory response, as evidenced by elevated CRP level, might have a key role in the progression of malnutrition and even cachexia in gastric cancer (Fearon et al, 2006; Crumley et al, 2010).

The GPS, which is based on both serum elevation of CRP and hypoalbuminemia, may enable a better appreciation of the effects of the tumour on both ongoing systemic inflammation and malnutrition. The GPS has been introduced to predict the prognosis of patients with very advanced neoplasms (Ishizuka et al, 2009; Shimoda et al, 2010). Recently, Nozoe et al (2011) studied the significance of the GPS in 232 patients with operable gastric cancer and demonstrated the prognostic value of the GPS in these patients. The present study revealed that a higher mGPS was associated with poorer survival in patients with advanced gastric cancer (stage II, III and IV), which is in accordance with the results of previous studies evaluating the prognostic value of the mGPS in gastric and other cancers. In the present study, 268 patients were diagnosed as pathological stage IV gastric cancer according to seventh UICC TNM staging system of gastric cancer. These patients received gastrectomy either because they were not classified as stage IV gastric cancer preoperatively or they needed to receive palliative gastrectomy because of complications related to gastric cancer. On the other hand, interestingly, the present study also showed the significant survival differences depending on the mGPS in patients with relatively early-stage gastric cancer (stage I). In the 997 patients with stage I gastric cancer, the 5-year survival rates for patients with an mGPS of $0(n=961), 1(n=30)$ and $2(n=6)$ were $93.0 \%$, $82.8 \%$ and $66.7 \%$, respectively (data not shown). Thus, the mGPS might also have prognostic value for survival in patients with relatively early-stage gastric cancer. However, the rate of mGPS 2 in patients with stage I gastric cancer was so low that it is too early to give a definite conclusion. Accumulation of more cases with mGPS 2 in stage I gastric cancer and survey of cancer-specific survival are warranted.

The results of the present study indicate that the mGPS may be a novel and simple biomarker in patients with gastric cancer. The findings of the present study may translate to potential improvements in the therapy of gastric cancer. For example, an mGPS of 2 was associated with very poor survival in the present study, so, for patients with both very advanced gastric cancer and an mGPS of 2, neoadjuvant chemotherapy may be beneficial. Similarly, these patients may require more aggressive adjuvant chemotherapy, such as S-1 plus cisplatin (Kodera et al, 2010). On the other hand, as patients with a higher mGPS had inflammatory response and/or malnutrition, anti-inflammatory therapy or nutritional support may have a beneficial effect on prognosis. It remains to be established whether patients with a higher mGPS need more active therapy.

In summary, the preoperative mGPS is a simple and useful prognostic factor for postoperative survival in patients with gastric cancer. The mGPS may be used together with traditional risk factors to individualise treatment strategies and the follow-up of patients with gastric cancer.

\section{ACKNOWLEDGEMENTS}

The study was approved by the Research Ethics Committee of Japanese Foundation of Cancer Research.

\section{Conflict of interest}

The authors declare no conflict of interest. 


\section{REFERENCES}

Al-Shaiba R, McMillan DC, Angerson WJ, Leen E, McArdle CS, Horgan P (2004) The relationship between hypoalbuminaemia, tumour volume and the systemic inflammatory response in patients with colorectal liver metastases. Br J Cancer 91: 205-207

Crew KD, Neugut AI (2006) Epidemiology of gastric cancer. World J Gastroenterol 12: 354-362

Crumley AB, McMillan DC, McKernan M, McDonald AC, Stuart RC (2006) Evaluation of an inflammation-based prognostic score in patients with inoperable gastro-oesophageal cancer. Br J Cancer 94: 637-641

Crumley AB, Stuart RC, McKernan M, McMillan DC (2010) Is hypoalbuminemia an independent prognostic factor in patients with gastric cancer? World J Surg 34: 2393-2398

Elahi MM, McMillan DC, McArdle CS, Angerson WJ, Sattar N (2004) Score based on hypoalbuminemia and elevated C-reactive protein predicts survival in patients with advanced gastrointestinal cancer. Nutr Cancer 48: $171-173$

Fearon KC, Voss AC, Hustead DS (2006) Definition of cancer cachexia: effect of weight loss, reduced food intake, and systemic inflammation on functional status and prognosis. Am J Clin Nutr 83: 1345-1350

Inoue M, Tsugane S (2005) Epidemiology of gastric cancer in Japan. Postgrad Med J 81: 419-424

Ishizuka M, Nagata H, Takagi K, Kubota K (2009) Influence of inflammation-based prognostic score on mortality of patients undergoing chemotherapy for far advanced or recurrent unresectable colorectal cancer. Ann Surg 250: 268-272

Jagdev SP, Gregory W, Vasudev NS, Harnden P, Sim S, Thompson D, Cartledge J, Selby PJ, Banks RE (2010) Improving the accuracy of preoperative survival prediction in renal cell carcinoma with $\mathrm{C}$-reactive protein. Br J Cancer 103: 1649-1656

Kamangar F, Dores GM, Anderson WF (2006) Patterns of cancer incidence, mortality, and prevalence across five continents: defining priorities to reduce cancer disparities in different geographic regions of the world. J Clin Oncol 24: 2137-2150

Kim DK, Oh SY, Kwon HC, Lee S, Kwon KA, Kim BG, Kim SG, Kim SH, Jang JS, Kim MC, Kim KH, Han JY, Kim HJ (2009) Clinical significances of preoperative serum interleukin-6 and C-reactive protein level in operable gastric cancer. BMC Cancer 9: 155

Kobayashi T, Teruya M, Kishiki T, Endo D, Takenaka Y, Tanaka H, Miki K, Kobayashi K, Morita K (2008) Inflammation-based prognostic score, prior to neoadjuvant chemoradiotherapy, predicts postoperative outcome in patients with esophageal squamous cell carcinoma. Surgery 144: 729-735

Kodera Y, Ishiyama A, Yoshikawa T, Kinoshita T, Ito S, Yokoyama H, Mochizuki Y, Ito H, Tsuburaya A, Sakamoto J, Nakao A (2010) A feasibility study of postoperative chemotherapy with S-1 and cisplatin (CDDP) for gastric carcinoma (CCOG0703). Gastric Cancer 13: 197-203
Koike Y, Miki C, Okugawa Y, Yokoe T, Toiyama Y, Tanaka K, Inoue $\mathrm{Y}$, Kusunoki M (2008) Preoperative C-reactive protein as a prognostic and therapeutic marker for colorectal cancer. J Surg Oncol 98: 540-544

Lai CC, You JF, Yeh CY, Chen JS, Tang R, Wang JY, Chin CC (2010) Low preoperative serum albumin in colon cancer: a risk factor for poor outcome. Int J Colorectal Dis 26(4): 473-481

Leitch EF, Chakrabarti M, Crozier JE, McKee RF, Anderson JH, Horgan PG, McMillan DC (2007) Comparison of the prognostic value of selected markers of the systemic inflammatory response in patients with colorectal cancer. Br J Cancer 97: 1266-1270

Lien YC, Hsieh CC, Wu YC, Hsu HS, Hsu WH, Wang LS, Huang MH, Huang BS (2004) Preoperative serum albumin level is a prognostic indicator for adenocarcinoma of the gastric cardia. J Gastrointest Surg 8: 1041-1048

McArdle PA, Qayyum T, McMillan DC (2010) Systemic inflammatory response and survival in patients with localised prostate cancer: 10 -year follow-up. Urol Int 84: 430-435

McMillan DC (2009) Systemic inflammation, nutritional status and survival in patients with cancer. Curr Opin Clin Nutr Metab Care 12: 223-226

Nozoe T, Iguchi T, Egashira A, Adachi E, Matsukuma A, Ezaki T (2011) Significance of modified Glasgow prognostic score as a useful indicator for prognosis of patients with gastric carcinoma. Am J Surg 201: 186-191

Nozoe T, Saeki H, Sugimachi K (2001) Significance of preoperative elevation of serum C-reactive protein as an indicator of prognosis in esophageal carcinoma. Am J Surg 182: 197-201

Richards CH, Leitch EF, Horgan PG, Anderson JH, McKee RF, McMillan DC (2010) The relationship between patient physiology, the systemic inflammatory response and survival in patients undergoing curative resection of colorectal cancer. $\mathrm{Br}$ J Cancer 103: 1356-1361

Roxburgh CS, McMillan DC (2010) Role of systemic inflammatory response in predicting survival in patients with primary operable cancer. Future Oncol 6: 149-163

Roxburgh CS, Salmond JM, Horgan PG, Oien KA, McMillan DC (2009) Comparison of the prognostic value of inflammation-based pathologic and biochemical criteria in patients undergoing potentially curative resection for colorectal cancer. Ann Surg 249: 788-793

Sasako M, Sano T, Yamamoto S, Kurokawa Y, Nashimoto A, Kurita A, Hiratsuka M, Tsujinaka T, Kinoshita T, Arai K, Yamamura Y, Okajima K (2008) D2 lymphadenectomy alone or with para-aortic nodal dissection for gastric cancer. $N$ Engl J Med 359: 453-462

Shimoda M, Katoh M, Kita J, Sawada T, Kubota K (2010) The glasgow prognostic score is a good predictor of treatment outcome in patients with unresectable pancreatic cancer. Chemotherapy 56: 501-506

Washington K (2010) 7th edition of the AJCC cancer staging manual: stomach. Ann Surg Oncol 17: 3077-3079

This work is published under the standard license to publish agreement. After 12 months the work will become freely available and the license terms will switch to a Creative Commons Attribution-NonCommercial-Share Alike 3.0 Unported License. 